\section{Commentary: Predicting coronary obstruction-Better good than lucky}

\author{
J. James Edelman, MBBS(Hons), PhD, ${ }^{a}$ \\ Jaffar M. Khan, BM, BCh, ${ }^{\text {b,c }}$ and \\ Vinod H. Thourani, MD
}

Coronary obstruction (CO), although rare, is a devastating complication of transcatheter aortic valve replacement (TAVR) and is associated with high mortality. It occurs more frequently in the placement of a TAVR valve for a failed surgical bioprosthesis $(2.3 \%)$ than in native valve TAVR $(<1 \%) .{ }^{1,2}$ In today's practice, 1 dimensional measurements should not be used in the final assessment for $\mathrm{CO}$ risk. There may arise scenarios in which low coronary artery heights from the aortic annulus may have capacious sinuses and not pose a significant risk for CO. Conversely, patients may present with narrow sinuses in which coronary arteries arise above the maximal height of the native (or bioprosthetic) leaflets. The anatomy of the aortic root, the length of the aortic valve leaflets, the distance of the coronary ostia from the aortic annulus, and the type of implanted transcatheter heart valve thus must be taken together to assess $\mathrm{CO}$ risk. Investigators in the BASILICA (Bioprosthetic or native Aortic Scallop Intentional Laceration to prevent Iatrogenic Coronary Artery obstruction during TAVR) investigational device exemption trial used an integrative approach to identifying patients at high risk of $\mathrm{CO} .{ }^{3}$ Patients were deemed to be at high risk for $\mathrm{CO}$ when the native or bioprosthetic leaflets fell above the coronary arteries (or the sinotubular junction) at their maximal height and when the horizontal distance

\footnotetext{
From the a Department of Cardiac Surgery, MedStar Heart and Vascular Institute, Georgetown University, Washington, DC; ' $S$ Section of Interventional Cardiology, MedStar Washington Hospital Center, Washington, DC; 'Cardiovascular Branch, Division of Intramural Research, National Heart Lung and Blood Institute, National Institutes of Health, Bethesda, Md; and ${ }^{\mathrm{d}}$ Department of Cardiovascular Surgery, Marcus Heart and Vascular Center, Piedont Heart Institute, Atlanta, Ga.

Disclosures: Authors have nothing to disclose with regard to commercial support.

Received for publication Oct 17, 2019; revisions received Oct 17, 2019; accepted for publication Oct 18, 2019; available ahead of print Oct 31, 2019.

Address for reprints: Vinod H. Thourani, MD, Department of Cardiovascular Surgery, Piedmont Heart Institute, 95 Collier Rd, Suite 5015, Atlanta, GA 30308 (E-mail: Vinod.Thourani@piedmont.org).

J Thorac Cardiovasc Surg 2021;162:1084-5

0022-5223/\$36.00

Copyright (c) 2019 by The American Association for Thoracic Surgery

https://doi.org/10.1016/j.jtcvs.2019.10.092
}

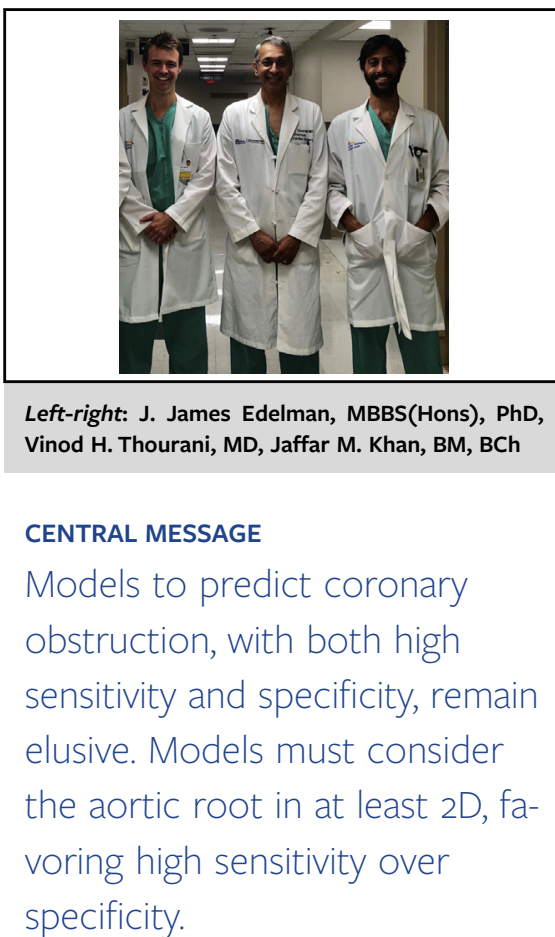

between the leaflet and the coronary artery (or sinotubular junction) was reduced when a virtual valve was implanted. ${ }^{3}$

In this issue of the Journal, Heitkemper and colleagues ${ }^{4}$ describe another model that uses 2-dimensional (2D) anatomic characteristics measured from computed tomography $(\mathrm{CT})$. The same group also described a 3-dimensional model to predict the same distance ${ }^{5}$; the group's 2D model described in this issue of the Journal ${ }^{4}$ is a simplified version of this model that is thought to be a better, more practical screening tool for the heart team's risk assessment. Their 2D model achieved a better sensitivity $(85 \%)$ and specificity than using coronary height $(<10 \mathrm{~mm})$ and sinus diameter $(<30 \mathrm{~mm})$ alone. A coronary height of less than $12 \mathrm{~mm}$, however, had a sensitivity of $100 \%$.

The problem with these models is that very few patients with CO from TAVR are included, because, appropriately, the heart team excluded "high-risk" patient populations whom they considered were likely to encounter this dreaded complication. In this analysis of Heitkemper and colleagues, ${ }^{4}$ only 1 patient had $\mathrm{CO}$, and 2 were intraoperatively considered to be at risk of $\mathrm{CO} .{ }^{4}$ In the analysis of Ribeiro and associates $^{2}$ that determined coronary artery height and sinus width to be high-risk factors, 28 patients had coronary artery obstruction and preprocedural CT data available. There is a desperate need for a large registry of patients who have had preprocedural CT scans and then 
had CO develop from TAVR so that these models can be validated.

There are other challenges with predicting $\mathrm{CO}$ after TAVR. Assumptions about the path of the native leaflet on valve expansion, which may vary in terms of calcification (thus width), and degree of prosthesis expansion are crude at best. Delayed CO, occurring after the patient has left an operating room after successful TAVR, may occur in $0.18 \%$ of native valve TAVR and is similarly difficult to predict.

We congratulate Heitkemper and colleagues ${ }^{4}$ for their continued work to improve prediction of $\mathrm{CO}$ after TAVR. We believe, given the devastating consequences of CO, that models should favor a high sensitivity over specificity. This is especially important as the age and risk profiles of patients undergoing TAVR decrease. Teams should consider techniques such as BASILICA (or referral to centers that perform this) or surgical aortic valve replacement if there is potential for obstruction.

\section{References}

1. Ribeiro HB, Rodés-Cabau J, Blanke P, Leipsic J, Kwan Park J, Bapat V, et al. Incidence, predictors, and clinical outcomes of coronary obstruction following transcatheter aortic valve replacement for degenerative bioprosthetic surgical valves: insights from the VIVID registry. Eur Heart J. 2018;39:687-95.

2. Ribeiro HB, Webb JG, Makkar RR, Cohen MG, Kapadia SR, Kodali S, et al. Predictive factors, management, and clinical outcomes of coronary obstruction following transcatheter aortic valve implantation: insights from a large multicenter registry. J Am Coll Cardiol. 2013;62:1552-62.

3. Khan JM, Greenbaum AB, Babaliaros VC, Rogers T, Eng MH, Paone G, et al. The BASILICA trial: prospective multicenter investigation of intentional leaflet laceration to prevent TAVR coronary obstruction. JACC Cardiovasc Interv. 2019;12:1240-52.

4. Heitkemper M, Hatoum H, Dollery J, Lilly SM, Dasi LP. Simple 2-dimensional anatomic model to predict the risk of coronary obstruction during transcatheter aortic valve replacement. J Thorac Cardiovasc Surg. 2021;162:1075-83.e1.

5. Heitkemper M, Hatoum H, Azimian A, Yeats B, Dollery J, Whitson B, et al Modeling risk of coronary obstruction during transcatheter aortic valve replacement. J Thorac Cardiovasc Surg. May 17, 2019 [Epub ahead of print].
See Article page 1075.

\section{Commentary: Preprocedural diagnostic imaging for transcatheter aortic valve implantation-Videri quam esse}

Keshava Rajagopal, MD, $\mathrm{PhD}$

Esse quam videri: To be, rather than to seem.

Videri quam esse: To seem, rather than to be.

Transcatheter aortic valve implantation (TAVI)-related technology and techniques have rapidly evolved and improved almost continuously since the initial work of

From the Department of Advanced Cardiopulmonary Therapies and Transplantation, McGovern Medical School, University of Texas-Houston, Houston, Tex.

Disclosures: Author has nothing to disclose with regard to commercial support.

Received for publication Sept 27, 2019; revisions received Sept 27, 2019; accepted

for publication Sept 27, 2019; available ahead of print Oct 8, 2019.

Address for reprints: Keshava Rajagopal, MD, PhD, 6400 Fannin, Suite 2350, Hous-

ton, TX 77030 (E-mail: keshava.rajagopal@uth.tmc.edu).

J Thorac Cardiovasc Surg 2021;162:1085-6

$0022-5223 / \$ 36.00$

Copyright (c) 2019 by The American Association for Thoracic Surgery

https://doi.org/10.1016/j.jtcvs.2019.09.125

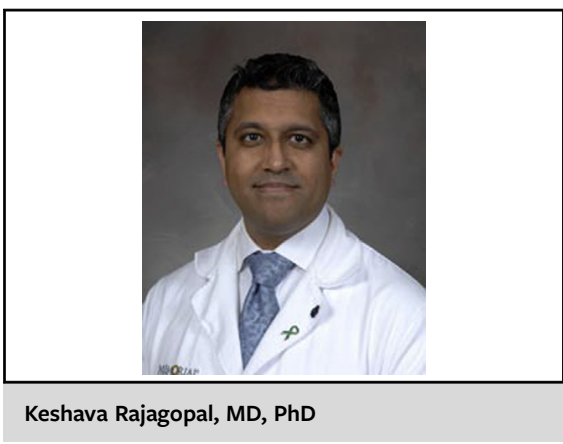

CENTRAL MESSAGE

Coronary arterial complications

are major adverse sequelae of

transcatheter aortic valve im-

plantation. Different approaches

to ascertaining risks of such

complications exist, each of

which has flaws.

Cribier almost 2 decades ago. As expected, the benefits of TAVI have increased, the risks have decreased, and the indications have consequently expanded. Several important complications continue to exist, however, the risks of which may be anticipated by diagnostic studies. Coronary arterial ostial complications are noteworthy among these because of 